\title{
A factor analysis to detect factors influencing building national brand
}

\author{
Naser Azad*, Somayeh Hozouri, Seyed Foad Zarifi and Yaser Khodashenas
}

Department of Management, Islamic Azad University, South Tehran Branch, Tehran, Iran

\section{H R O N I C L E A B S T RAC T}

Article history:

Received October 28, 2012

Received in revised format

20 January 2013

Accepted 10 February 2013

Available online

February 112013

Keywords:

Factor analysis

National brand

Iran Khodro

\begin{abstract}
Developing a national brand is one of the most important issues for development of a brand. In this study, we present factor analysis to detect the most important factors in building a national brand. The proposed study uses factor analysis to extract the most influencing factors and the sample size has been chosen from two major auto makers in Iran called Iran Khodro and Saipa. The questionnaire was designed in Likert scale and distributed among 235 experts. Cronbach alpha is calculated as $84 \%$, which is well above the minimum desirable limit of 0.70 . The implementation of factor analysis provides six factors including "cultural image of customers", "exciting characteristics”, "competitive pricing strategies”, "perception image” and "previous perceptions".
\end{abstract}

(C) 2013 Growing Science Ltd. All rights reserved.

\section{Introduction}

Brand is one of the most important components of business development in retain industry. In fact, many retail industries spend significant amount of cost and efforts for marketing in two national and domestic levels. Building a domestic brand plays an important to exposure some products in Iranian market. These days, we see many retail sellers who offer Iranian products domestically with other well-known international brands. This issue is getting more important in close industry where people are more interested in purchasing Turkish products even if Iranian ones present better quality. One important issue in this market is to learn how to build an acceptable brand such that people could trust. There are literally various studies associated with building brand in societies. According to Barron and Hollingshead (2004), companies that wish to build truly global brands must go through three steps. They need to develop a various process for coordinating brand development, revise consumer research framework, and clearly describe the relationship between the center and the regions. They state that implementing a different method for understanding consumers goes a long way toward facilitating agreement across markets and alignment of the brand versus common consumer segments.

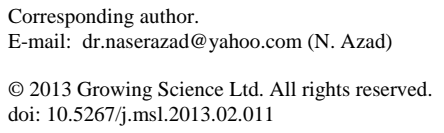


Konecnik and Gartner (2007) presented the concept of customer-based brand equity and implemented it to a destination. The theoretically proposed and empirically verified framework complements previous research findings on a destination's evaluation from the tourist's perspective. They reported that an image plays an important role in evaluation but is not the only brand dimension that should be considered and brand equity differed between the markets based on their evaluation of brand dimensions. Breazeale and Ponder (2011) reported five categories of relationships, which differ on perceived self-image congruity and involvement including Perfect Matches, Mismatches, FairWeather Friends, Best Friends, and Acquaintances for consumers' relationships with brands.

Shukla and Purani (2012) provided some evidence to the much conceptualized but not-yet-tested model of luxury value perceptions in cross-national context. They used five distinct parameters and compared the luxury value perceptions among British and Indian consumers. Their results provided some insights between collectivist and individualistic markets and supported the notion that various luxury value perceptions may be highly influential in any country. They recommended that consumers in collectivist markets implement simpler selection criteria for measuring value of a luxury brand than consumers in individualistic markets. The results may help luxury brand managers develop a coherent and integrated long-term global strategy, which also takes in country-specific adjustments.

Amrouche and Yan (2012) proposed a game-theoretic framework in three contexts of national brand (NB), private label (PL) and NB's manufacturer opening an online store. They reassessed the advantage of introducing the PL and studied the profitability of using an online store. They found that the retailer was not always enjoying the PL's introduction and the manufacturer could take advantage of this strategy. Karray and Martín-Herrán (2009) studied the relationship between the pricing and advertising decisions in a channel where a national brand was competing with a private label. They considered a differential game, which incorporated the carryover impacts of brand advertising over time for both the manufacturer and the retailer. They used equilibrium Markov strategies and explained that the relationship between advertising and pricing decisions in the channel depended mainly on the nature of the advertising influences.

Romaniuk et al. (2007) provided an empirically grounded theoretical argument, which played a more limited role in brand competition than the orthodox literature assumes. LaTour et al. (2010) investigated consumers' childhood memories with Coca-Cola and reported that memories from early childhood were more predictive and insightful for understanding current brand attitudes than memories coming from adolescence.

Valette-Florence et al. (2011) evaluated the relative effect of a long-term brand management instrument and a short-term marketing mix instrument on brand equity formation. They measured consumer perceptions of promotional intensity and brand personality and model their effect on brand equity and reported a positive effect of brand personality and a negative effect of sales promotion intensity on brand equity at the aggregate level. Buil et al. (2008) investigated the measurement invariance of the consumer-based brand equity scale across two instances of UK and Spanish consumers. They reported that the consumer-based brand equity scale maintained similar dimensionality and factor structure across countries and consumers responded to the items of brand equity in the same way, which allowed meaningful comparison of scores.

This paper presents a survey to study various factors affecting brand development using factor analysis, which has recently become a popular method. For example, Azad et al. (2013) investigated the impact of new methods of advertisement in product development. Azad and Masoumi (2013) presented important factors impacting competitive advantage. Azad et al. (2012) proposed an empirical investigation to learn more about challenges in carpet industry using factor analysis. 


\section{The proposed study}

This study attempts to find the impact of national brand strategy on creating consumers' excitement to prefer national brand versus other products. The proposed study uses factor analysis to extract the most influencing factors and the sample size has been chosen from two major auto makers in Iran called Iran Khodro and Saipa. The questionnaire was designed in Likert scale and distributed among 235 people. Cronbach alpha is calculated as $84 \%$, which is well above the minimum desirable limit of 0.70 . There are 25 variables and using factor analysis, we extract six factors where Kaiser-MeyerOlkin Measure of Sampling Adequacy was 56.4\% (Chi-Square $=3200 \mathrm{df}=300 \mathrm{Sig} .=0.000$ ), which also confirms the results of our survey.

\section{The results}

The results of the implementation of factor analysis have provided six factors including "cultural image of customers", "exciting characteristics", "competitive pricing strategies", "perception image” and "previous perceptions" and "physical characteristics" explained next.

\subsection{Cultural image}

The first factor is known as cultural image, which includes five sub-factor including the effects of nation and culture on using luxury products, national security, consumer perception from different brands, cultural differences and consumer intention for purchasing a product. Table 1 shows the weights for all factors and the results indicate that "national security" is number one important factor followed by "the effects of nation and culture on using luxury products", "consumer perception from different brands”, “consumer intention for purchasing a product” and cultural differences.

\section{Table 1}

The summary of factor analysis for cultural image

\begin{tabular}{lcccc}
\hline Option & Factor weight & Eigenvalues & \% of variance & Accumulated \\
\hline $\begin{array}{l}\text { The effects of nation and culture on using } \\
\text { luxury products }\end{array}$ & 0.798 & & & \\
National security & 0.803 & 2.433 & 48.657 & 48.657 \\
Consumer perception from different brands & 0.684 & & \\
Cultural differences & 0.563 & & \\
Consumer intention for purchasing a product & 0.605 & & \\
\hline
\end{tabular}

\subsection{Exciting characteristics}

Exciting characteristics is the second item with four components including physical characteristics of brand, emotional components, creating a myth and increase in visual stimuli on retail space. Table 2 shows the weights for four factors and the results demonstrate that physical characteristics of a brand is the most important subcomponent followed by increase in visual stimuli on retail space and creating a myth. Cronbach alpha is equal to 0.732 , which is well above the minimum desirable limit.

Table 2

The summary of factor analysis for exciting characteristics

\begin{tabular}{lcccc}
\hline Option & Factor weight & Eigenvalues & \% of variance & Accumulated \\
\hline Physical characteristics of brand & 0.83 & 2.226 & 55.643 & 55.643 \\
Emotional components & 0.689 & & & \\
Creating a myth & 0.692 & & & \\
Increase in visual stimuli on retail space & 0.724 & & & \\
\hline
\end{tabular}




\subsection{Competitive pricing strategies}

Competitive pricing strategies is the third factor, which includes three factors including "pricing strategies", "Social commitments" and "Providing the lowest price". Table 3 demonstrates the weights for all factors and the results clearly demonstrate that "relationship between product characteristics" is the most important items in this part of our survey followed by "using multimedia advertisements” and "using several retail stores” where Cronbach alpha is equal to 0.738.

\section{Table 3}

The summary of factor analysis for competitive pricing strategies

\begin{tabular}{lcccc}
\hline Option & Factor weight & Eigenvalues & $\%$ of variance & Accumulated \\
\hline $\begin{array}{l}\text { Relationship between product } \\
\text { characteristics }\end{array}$ & 0.752 & & & \\
\hline $\begin{array}{l}\text { Using multimedia advertisements } \\
\text { Meeting customers' benefits }\end{array}$ & 0.801 & & & \\
\hline
\end{tabular}

\subsection{Perception image}

Perception image is the next factor with three sub-factors including "perception image based on the knowledge”, “consumer image's perception” and "intangible characteristics of retailors". Table 4 presents the weights for all factors and the results show that the first factor, "perception image based on the knowledge", is the most important items in this part of our survey and Cronbach alpha is calculated as 0.60 .

\section{Table 4}

The summary of factor analysis for product advantage

\begin{tabular}{lcccc}
\hline Option & Factor weight & Eigenvalues & $\%$ of variance & Accumulated \\
\hline $\begin{array}{l}\text { Perception image based on the } \\
\text { knowledge }\end{array}$ & 0.830 & 1.853 & 61.781 & 61.781 \\
$\begin{array}{l}\text { Consumer image's perception } \\
\begin{array}{l}\text { Intangible characteristics of } \\
\text { retailors }\end{array}\end{array}$ & 0.785 & & & \\
\hline
\end{tabular}

\subsection{Previous perception}

Previous perception is the fifth factor with three sub-factors including "trust to brand", "initial experience from a brand" and "social commitments". Table 5 describes the weights for all three factors and the results indicate that the first factor, "Social commitment", is the most important items in this part of our survey and Cronbach alpha is equal to 0.66 .

\section{Table 5}

The summary of factor analysis for previous perception

\begin{tabular}{lcccc}
\hline Option & Factor weight & Eigenvalues & $\%$ of variance & Accumulated \\
\hline Trust to brand & 0.802 & & & \\
Initial experiences from a brand & 0.756 & & & \\
Social commitments & 0.813 & 1.877 & 62.551 & 62.551 \\
\hline
\end{tabular}

\subsection{Physical characteristics}

Physical characteristics is the last factor with two sub-factors including "tangible characteristics" and "retail chain". Table 6 describes the weights for both factors and the results indicate that the first 
factor, "tangible characteristics", is the most important items in this part of our survey and Cronbach alpha is equal to 0.421 .

Table 6

The summary of factor analysis for physical characteristics

\begin{tabular}{lcccc}
\hline Option & Factor weight & Eigenvalues & \% of variance & Accumulated \\
\hline Tangible characteristics & 0.796 & 1.269 & 63.427 & 63.427 \\
Retail chain & 0.796 & & & \\
\hline
\end{tabular}

\section{Conclusion}

Developing a national brand is one of the most important issues for development of a brand. In this study, we have implemented factor analysis to detect the most important factors in building a national brand. The implementation of factor analysis has provided six factors including "cultural image of customers", "exciting characteristics”, “competitive pricing strategies”, "perception image” and "previous perceptions".

The first factor, “cultural image of customers", included six components where "national security" was number one important factor followed by "the effects of nation and culture on using luxury products", "consumer perception from different brands", "consumer intention for purchasing a product" and cultural differences. The second factor, "exciting characteristics", demonstrated that physical characteristics of a brand was the most important subcomponent followed by increase in visual stimuli on retail space and creating a myth.

The third factor, "competitive pricing strategies", and the implementation of factor analysis has indicated that "relationship between product characteristics" was the most important items in this part of our survey followed by "using multimedia advertisements" and "using several retail stores". The fifth factor, "previous perceptions" and it includes that "Social commitment", was the most important items of this components. Finally, Physical characteristic was the last factor with two sub-factors including "tangible characteristics" and "retail chain" and tangible characteristics played more influencing role.

\section{Acknowledgment}

The authors would like to thank the anonymous referees for constructive comments on earlier version of this paper.

\section{References}

Azad, N., \& Masoumi, M. (2012). The impact of packaging on product competition. Management Science Letters, 2(8), 2789-2794.

Azad, N., Seyed Aliakbar, S.M., \& Ansari, M. (2012). Investigating knowledge management critical success factors in carpet industry. Management Science Letters, 2(8), 2717-2722.

Azad, N., Zarifi, S.F., Hozori, S., \& Hashemi, S. (2013). A survey on critical factors influencing new advertisement methods. Management Science Letters, 3(2), 569-574.

Barron, J., \& Hollingshead, J. (2004). Brand globally, market locally. Journal of Business Strategy, 25(1), 9-14.

Konecnik, M., \& Gartner, W. C. (2007). Customer-based brand equity for a destination. Annals of Tourism Research, 34(2), 400-421.

Breazeale, M., \& Ponder, N. (2011). Get the picture? Visual servicescapes and self-image congruity. Journal of Business Research doi: 10.1016/j.jbusres.2011.06.009 
Shukla, P., \& Purani, K. (2012). Comparing the importance of luxury value perceptions in crossnational contexts. Journal of Business Research, 65(10), 1417-1424.

Amrouche, N., \& Yan, R. (2012). Implementing online store for national brand competing against private label. Journal of Business Research, 65(3), 325-332.

Karray, S., \& Martín-Herrán, G. (2009). A dynamic model for advertising and pricing competition between national and store brands. European Journal of Operational Research, 193(2), 451-467.

Romaniuk, J., Sharp, B., \& Ehrenberg, A. (2007). Evidence concerning the importance of perceived brand differentiation. Australasian Marketing Journal (AMJ), 15(2), 42-54.

LaTour, K., LaTour, M. S., \& Zinkhan, G. M. (2010). Coke is It: How stories in childhood memories illuminate an icon. Journal of Business Research, 63(3), 328-336.

Valette-Florence, P., Guizani, H., \& Merunka, D. (2011). The impact of brand personality and sales promotions on brand equity. Journal of Business Research, 64(1), 24-28.

Buil, I., de Chernatony, L., \& Martínez, E. (2008). A cross-national validation of the consumer-based brand equity scale. Journal of Product \& Brand Management, 17(6), 384-392. 